\title{
KNOWLEDGE MANAGEMENT - A NECESSITY FOR THE TRAINING OF FUTURE SPECIALISTS OF THE SUSTAINABLE ENTREPRISES
}

\author{
ROTARU Ionela Magdalena \\ assistant professor Ph.D., Faculty of Engineering/Department Industrial Engineering and Management., \\ "Lucian Blaga" University, Sibiu, Romania, ionela.rotaru@ulbsibiu.ro
}

\begin{abstract}
The world we are living in is shaped by what is a reality for years already: globalisation of economy. The lack of borders makes the impact that technology has on society to be a major one. The virtual world so accessible today is not just about new markets, access to cheaper work force, work online but also fierce competition. The common denominator of most efforts in the area of industry is performance. Limits continuously moving willingness to pay for products that delineate the performance delivered be the same range. Here too we can see the role of the education. For example, Landes ${ }^{1}$ shows that both knowledge and know-how are the ones that determine how well off societies are. The education of engineers is therefore critical to every nation to ensure the prosperity of its citizens. This paper here intends to approach the educational process of the engineering specific area of knowledge from the management perspective. The training process becomes sustainable in accordance with the requirements of the future: trained specialists for sustainable enterprises.
\end{abstract}

Key words: knowledge management, engineering education, sustainable development, knowledge models, manufacturing technology.

\section{Introduction}

The organisations of the future are those that identify with the principles of the sustainability that largely we can define as the "development that meets the needs of the present without compromising the future generations to meet their own needs" [8].

The principles of the sustainability are found in companies applied both in production technologies as well as at the management level.As sustainable manufacturing technologies we encounter those relating to: optimisations that aim to reduce the consumption of the energy like - process parameters optimisation, cutting path optimisation, cutting fluid optimisation; dry cutting, little quantity lubricant, green design, design based on knowledge management, selections based on reducing energy consumption - manufacturing process selection, row material selection and others.

Thes present paper stops on the role of knowledge. We define organisational learning and knowledge system as the vehicle for utilizing past experiences, adapt to external changes and enable future options [1]. There are three major components of the structure of the organisational learning and knowlerdge system: organisational learning antecedents (or inputs), organizational learning process and organizational learning outcomes (or outputs) [4].

The present paper will focus on the first component. The importance of the knowledge level of the new employees resides in both the immediate level of the knowledge baggage they bring as well as a guarantee of the future acquisition that will be based on the learning process. And the learning outcomes are the consequences of the learning processes. Absortive capacity is the ability of a firm to recognize the value of a new, external information, asimilate it, and apply it to commercial ends that are critical to its innovative capabilities [2].

\section{Engineering education and its challanges}

"Today, the practice of engineering needs to change further because of the demands for tehnologies and products that exceed existing knowledge bases and because the changed profesional enviroment in witch engineers need to operate. That change must be encouraged and facilitated by change in engineering education" [7] iar Patricia Galloway arata ca "to remain competitive in this global and

\footnotetext{
${ }^{1}$ D.S.Landes, The Wealth and Poverty of Nations, Why Some are so rich and Some so Poor, New York, W.W. Norton \& Company, 1998.
} 
knowledge based economy and to ensure that the quality of life improves for everyone around the world, engineers must be educated differently [3].

The challenges encountered in the engineering education are the ones residing from the skills that we must find in the today engineers: "We have to change what we expect from engineers, and we have to turn out our graduates with broader skills, interests, and abilities...I need graduates who can speak before an audience to make a point...Engineers must be alble to write reports, studies...." [5].

Among the skills that should be aquired through years of study enroll: to understand, familiarizeze and use the tools an engineer need for engineering practice, to identify and formulate a problem, to gether information, to analize and interpret them in order to solve the problem (or to be capable to design and conduct an experiment single or as a part of a team if the problem supose that), to comunicate and so on. Still in order to achive these goals, a defining characteristic for engineering must be in the spotlight: the complex and multidisciplinar character of it. Solving of an engineering problem supposes the knowledgement and the connection making between specific concepts of various engineering area. Achieving these objectives is often difficult due to the global and sometimes abstract character of the issue.

\section{Knowledge Management}

A response to the issues raised is the knowledge menagement "Knowledge is not a picture of reality; it is much more a map of those actions that reality permits. It is a repertoire of concepts, semantic relationships and actions or operations that have proven to be viable for the attainment of our goals" [6]. Offering predefined solutions to existing problems, being characterised of a dinamic character (a model of knowledge is in a continous change) this is a powerful tool for capturing and transmitting the knowledge.

A particularly important aspect is the one that characterises the knowledge management is shaping each given problem by considering the fact that the knowledge transmitted in an explicit and articulated way, represents just a part of the volume of knowledge that is necessary to be transmitted (delivered). Transmitting (delivering) explicit knowledge is done using charts, diagrams, tables, theorems, equations. The rest of knowledge is transmitted by default (similar knowledge exploited for a given problem) or in a tacit way, a non-articulated chanal represented by videos, sketches, photos. In the educational plan this represents a solution through its instruments in identifying, collecting, sorting, storing and presenting of a high volume of concepts, information and data connected/ linked together. Using knowledge management at an educational level, will represent for the future engineer a possible connection with the possible situation he/she can find him/her-self athe the future working place, the knowledge management being one of the sustenability elements found at the enterprises elevel through its own nature - knowledge constitutes an unlimited source - as well as through the benefits brought based on its principles that we can use to create data bases, data models, decisional systems and so on that enables the knowledge to be a comun and transmisible tesaurus of companies.

In this ppaer we illustrate using a case study, how they can achieve knowledge transfer based on knowledge management. The subject matter will be a speciality one, reffering to the structure of the technologic process. The knowledge transfer will be done on two levels:

- The first one will cover the principles of knowledge management by identifying the knowledge/ information to be transmitted (defining knowledge for the given theme) and of the transmision of this information optimally according to their type: explicit, implicit or tacit knowledge;

- Ta the capturing, structuring, storing and presenting level of the concepts to be delivered by using the knowledge model, in this case the Concept Map.

The knowledge to be delivered as well as the adequate way to do it are schematically presented in Fig. 1 Types of knowledge and the way toi transmit them. We remark the transmission of the knowledge on the most adequate chanells so that in the case of the explicit knowledge we were using tables, charts, graphs. But to transmit tacit knowledge we used manufacturing processes, the discussion and the analyse based on the video recordings made with the manufacturing occasion. The implicit knowledge was transmitted by the conexion with resemblant subjects already knowned. Briefly the education method can be embodied on three important steps:

- preparation of the subject - the selection of the knowledge to be transmitted, identify optimal transmitting way, preparing the resources (blank material, equipment, films, charts, tables and so on) as well as preparing worksheets that will make recording during teaching;

- discussion and analisys of thecases submitted, checking the records made, achive the knowledge models by the students - in this case knowledge maps were made and by making them the 
participants found themselves in the situation to come back and review the knowledge they achieved, also they had to structure the knowledge based on logical connections and to present the knowledge in the shape of interconnected concepts that define in this way a given theme;

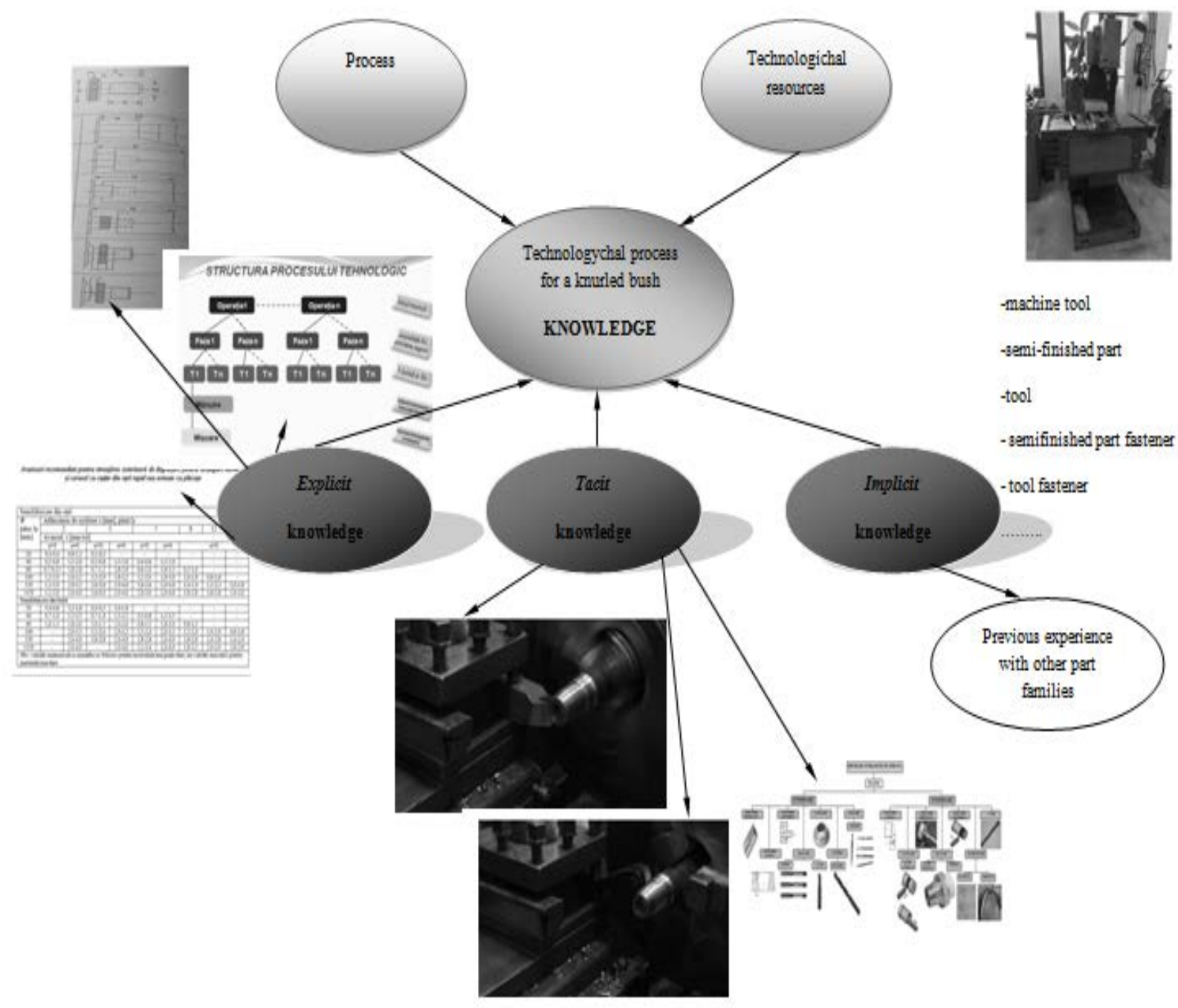

Figure 1: Knowledge types and their transmission channels

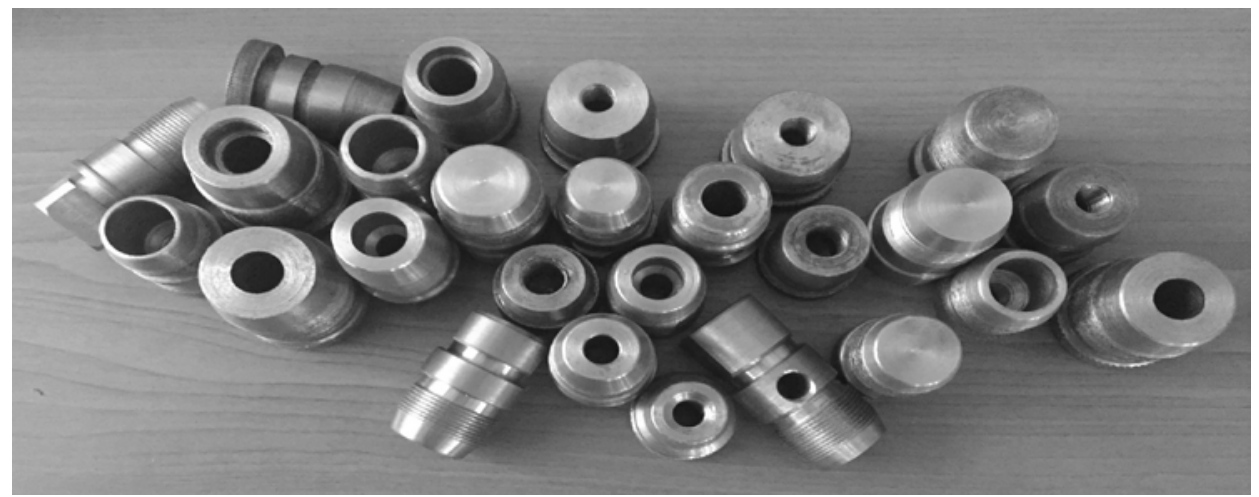

Figure 2: The part family used for test

- The evaluation of the achieved knowledge baggage is the last phase, this requires a landmark assesment recounted in the given test but before the presented steps to be shown (knowledge on the proposed topic were submitted classically). 


\section{Evaluation of the knowledge transferred}

The evaluation of the transfer of knowledge has experienced a pragmatic and clear form. Each participant received a part of the studied family Fig. 2. The part family used for test. Fort that part were taken into consideration: it was asked to elaborate and develop the structure of the technologic manufacturing process for the individual production case. The given theme was aimed to understand the request, the overview of the proposed problem and therefore the solution finding for problems like: the critical analisys of the manufacturing possibilities, the selection of the most apropriate methods, the understanding of the resources the manufacturing process supposes and the selection od the most adequate resources. To evaluate the proposed educational method it was used the methodology of preand post- test design. The subjects were 78 engineering students from the author didactical practice. The assesements of students skills was scored on four point Likert scale 1 - insufficient, 2 - satisfactory, 3 good and 4 very good. The students satisfaction was evaluated by a questionaire aiming to check the perception of the students over the proposed way of transfer of the knowledgement, making assesments on: notification of the atmosphere in the classroom, notification of the student's opinion on the proposed subjects, of the conexion between the subjects proposed and the subjects encountered in other disciplines and so on.

If in the initial test the results average stood around satisfying vales (6,69\% very good, $10,25 \%$ good, $69,23 \%$ satisfactory and $12,82 \%$ insufficient) from the post test results is seen a significant emprovement. The post test values are $19,23 \%$ very good, $38,46 \%$ good, $42,30 \%$ satisfactory.

The perception of the students over the teaching method was a positive one, the students commenting as it follows: "I liked the continous conexion with the practical/ working part", "I apreciated the free teacher-student conversations", "I liked the given themes, I learned by solving them and also I was checking myself".

\section{Conclusions}

The participants feed-back, materialised itself through the tests results of the students and through the personal perception of the students over the eductaional method used, all these advocate adopting the knowledge transfer based on the knowlegement management principles. The volume of knowledge assimilated by this kind of aproach is win both by the point of view of enriching the personal knowledge baggage as well as a step towards knowing methods that find themselves at this moment in the industry. The graduates will realise the principles and the importance of the knowledge management and they will achieve the ability to conceive knowledge models. This knowledge will be used in a future job for instance in the construction of the decision-making supports, these being ones of the most popular and accesed applications of the knowledge management.

\section{Acknowledgements}

This work was supported by the strategic grant POSDRU/159/1.5/S/133255, Project ID 133255 (2014), co-financed by the European Social Fund within the Sectorial Operational Program Human Resources Development 2007 - 2013.

\section{References}

1. Berends, H., Boersma, K., Weggeman, M., The structuration of organizational learning, Human Relations,Vol.56, pp. 1035 - 1056, (2003).

2. Cohen, W.M., Levinthal, D.A., Absortive capacity: a new perspective on learning and innovation., Administrative Science Quaterly,Vol.35, pp. 128 -152 (1990).

3. Galloway, Patricia, D., The 21st-Century Engineer: A Proposal For Engineering Education Reform, Civil Engineering, pp. 46 -49, (2007).

4. Gavronsski, Iuri, Klassen, D. Robert, Vachon, Stephan, et all, A learning and knowledge approach to sustenaible operations, Int.J. Production Economics,Vol.5, No.3, pp. 34 -41, (2009).

5. Kennedy, C. Theodore, "The Value-Added" Approach to Engineering Education: An Industry Perspective, The Bridge, Vol.36, No.5, pp. 14 - 16, (2006).

6. Meyer, Bertolt, Sugiyama, Kozo, The concept of knowledge in KM: a dimensional model, Journal of knowledge management, Vol.10, No.6, (2006).

7. National Academy of Engineering, Educating the Engineer of 2020: Adapting Engineering Education to the New Century, National Academies Press, pp. 13 (2005).

8. World Commission on Environment and Development, Our common future. Report, Oxford University Press, (1987). 